\title{
Promoting prompt help-seeking for symptoms - assessing the impact of a gynaecological cancer leaflet on presentations to primary care: a record- based randomised control trial
}

\author{
Jackie Campbell ${ }^{1 *}$, Kirty Vaghela ${ }^{2}$, Stephen Rogers ${ }^{3}$, Michelle Pyer ${ }^{4}$, Alice Simon ${ }^{5}$ and Jo Waller ${ }^{6}$
}

\begin{abstract}
Background: Information leaflets have been shown to significantly improve awareness of the symptoms of gynaecological cancers and to reduce perceived barriers to seeking medical help. This record-based, parallel, randomised control trial study aimed to assess whether receipt of a leaflet would change the behaviour of women experiencing symptoms indicative of gynaecological cancers by prompting them to visit their general practitioner (GP).

Methods: 15,538 women aged 40 years or over registered with five general practices in Northamptonshire, UK were randomised to two groups using the SystmOne randomise facility. Those in the intervention group received an educational leaflet from their general practice explaining the symptoms of gynaecological cancers and advising symptomatic women to visit their GP. The control group were not contacted. Electronic records were interrogated to extract sociodemographic data and details of GP consultations for symptoms, tests, referrals and diagnoses relating to gynaecological cancers in the 4-month period following the mail-out of the leaflets.
\end{abstract}

Results: 7739 records were extracted from the intervention group and 7799 from the control group. 231 (3.0\%) of the women in the intervention group, and 207 (2.7\%) of the controls, presented to their GP with a relevant symptom during the 4-month period following leaflet distribution. The slightly higher rate in the intervention group did not reach statistical significance at the $5 \%$ level $(\mathrm{RR}=1.11 ; 95 \% \mathrm{Cl} 0.92-1.33 ; \mathrm{z}=1.08 ; p=0.28)$. There was a significantly lower mean time to first presentation in the symptomatic intervention group (57.2 days, $s d=36.5$ ) compared to the control group (65.2 days, $\mathrm{sd}=35.0)(t=-2.415 ; p=0.016)$. Survival analysis did not reveal a difference between the patterns of presentation in the two cohorts (Log Rank (Mantel-Cox) $x^{2}=1.42 ; p=0.23$ ).

Conclusion: There was no difference between intervention and control groups in the proportion of women presenting with symptoms identified in the leaflet in the four months following leaflet distribution, although the women who had been sent a leaflet presented earlier than those in the control group. A larger study is needed to test for a modest effect of leaflet distribution.

Trial registration: Listed on the ISRCTN registry with study ID ISRCTN61738692 on 23-8-2017 (retrospectively registered). Keywords: Gynaecological, Cancer, Public health, General practice, Patient education

\footnotetext{
* Correspondence: jackie.campbell@northampton.ac.uk

${ }^{1}$ Faculty of Health and Society, University of Northampton, Northampton NN2 7AL, UK

Full list of author information is available at the end of the article
}

(c) The Author(s). 2018 Open Access This article is distributed under the terms of the Creative Commons Attribution 4.0 International License (http://creativecommons.org/licenses/by/4.0/), which permits unrestricted use, distribution, and reproduction in any medium, provided you give appropriate credit to the original author(s) and the source, provide a link to the Creative Commons license, and indicate if changes were made. The Creative Commons Public Domain Dedication waiver (http://creativecommons.org/publicdomain/zero/1.0/) applies to the data made available in this article, unless otherwise stated. 


\section{Background}

Gynaecological cancers (carcinomas of the ovary, cervix, uterus, vagina, vulva or endometrium) have a combined UK incidence second only to breast cancer [1]. Earlier diagnosis of gynaecological cancers is a key strategy in closing the survival gap between England and the European average [2]. Studies suggest that a main cause of the delay in diagnosis is deferral in presentation [3-5] which is thought to be driven in part by low symptom awareness [6, 7]. Symptoms are often attributed to benign causes [8], and medical help is not sought. The GP-patient relationship is also influential in decision-making: almost half the respondents to a survey using the Cancer Awareness Measure expressed worry about 'wasting the doctor's time', causing delays [9].

Leaflets can increase cancer awareness and knowledge [10-12]. However, few studies have examined whether increased awareness translates into changes in patient behaviour. There is evidence to suggest that information leaflets can increase attendance at screening [13] and reduce stroke delay [14]. Research here remains limited; no empirical research confirms that leaflets can promote symptom presentation to primary care clinicians.

An information leaflet detailing the symptoms of gynaecological cancers and encouraging women to present to their general practitioner with any concerns was developed using focus groups with experts, cancer survivors and the public [15]. It was tested with the public and shown to have at least a short-term impact; exposure to the leaflet reduced women's perceived barriers to help-seeking, increased symptom knowledge and reduced anticipated time to help-seeking [12].

This study aimed to investigate whether being sent this leaflet affects the rate and timing of presentation to primary care for symptoms indicative of gynaecological cancers.

\section{Methods}

\section{Participants and setting}

The research was conducted in five general practices across Northamptonshire, UK, chosen to include a range of socio-geographical factors and practice sizes. All practices used the SystmOne electronic patient record system. Registered female patients were eligible for inclusion if they were 40 years or over (the age group in whom the majority of gynaecological cancers occur) and were not on the oncology and palliative care, learning difficulties or mental health registers.

\section{Sampling}

Participants for the control and intervention (leaflet) groups were selected at random, without replacement, using the random selection facility within SystmOne from those women meeting the selection criteria. Approximately equal proportions of women were selected from each practice population, with equal numbers of control and intervention group participants. Those in each group were flagged using project-specific Read codes.

\section{Intervention}

The leaflet was developed by Morris et al. (2016) [12] through an iterative process involving experts, gynaecological cancer survivors and the public. It introduces the gynaecological cancers, listing their symptoms, together with a check-list for women to record any symptoms they have had. It concludes with a 'call to action' for women to make a GP appointment if they have any of the symptoms. The leaflet can be found as a supplementary file to Morris et al. (2016) [12].

The leaflet was mailed to the home address of each patient selected for the intervention arm in June 2014, along with a covering letter from their GP which introduced the research project and included the sentence "I hope it [the leaflet] will inform you about an important health message: gynaecological symptoms should be taken seriously at every age, and discussed with your doctor if they don't go away".

\section{Outcomes}

The primary outcome is the period prevalence rate for women over 40 presenting with relevant signs and symptoms within four months following distribution. We estimated the time to presentation up to four months following leaflet distribution for women seen with relevant signs and symptoms. We also calculated the proportion of women over 40 who were subsequently referred urgently for specialist assessment together with the time to urgent referral and noted gynaecological cancer diagnoses recorded during the study period, for descriptive analysis only.

\section{Sample size}

Previous research from surveys completed using Computer Assisted Personal Interviewing (CAPI) [16] indicates that $44 \%$ of women in the general population had symptoms indicative of gynaecological symptoms in the previous 3 months. Of these, 30\% had seen their GP about these symptoms. For a power of $95 \%$ of detecting a $13 \%$ increase in the attendance rate of symptomatic women seeing their GP (from 30 to 34\%), 3532 symptomatic women are required in each group $(\alpha=0.05)$. This effect size was considered to be clinically significant. As symptomatic women can be assumed to be $44 \%$ of the total sample group size, this required 8027 women to be selected for each of the two groups.

\section{Data extraction}

A SystmOne query was constructed using a list of over 200 Read codes which included all relevant codes relating 
to the symptoms in the leaflet (130 codes), diagnostic tests ordered, test results and referrals relating to gynaecological symptoms and possible gynaecological cancer diagnoses, together with demographic information.

Patients were identified by a unique, non-identifiable project number before data was extracted for a four month period, starting the day after the mail-out date for the leaflet for each practice. Read codes were grouped under higher order categories reflecting either the leaflet content (e.g. in relation to groups of symptoms) or meaningful clinical groupings that allow for variation in codes used between different GPs.

Ethnicity recording in general practice is known to be problematic [17]. 44.6\% (6926) of patients did not have their ethnicity recorded and, where it was, 91 different Read codes were used from 4 different code hierarchies. Only $4.8 \%$ of ethnicity records used the recommended 9S codes which map onto principal census categories. Comparison of ethnicities was therefore not attempted.

The GeoConvert utility [18] was used to map participant postcode districts against the Lower Layer Super Output Areas (LSOAs) within that district, together with the proportion of the district formed by each LSOA. This information was then used together with the Index of Multiple Deprivation (IMD) data for each LSOA [19] to calculate the weighted mean IMD score for each district, as a marker of area-level deprivation.

\section{Statistical analysis}

Age and IMD score were examined using descriptive statistics. The sample characteristics of the control and intervention arm were compared using Mann-Whitney tests.

For the primary outcome, a positive outcome was defined as at least one eligible symptom Read code event recorded for the patient within the four-month study period. Cochrane's z-tests were used to investigate differences in the proportions of women with positive outcomes in the two groups. Cochrane's z-test was also used for comparison of urgent referral rates.

Independent $\mathrm{t}$-tests were used (following confirmation of normality) for comparison of time to presentation and referral (there is no censored data for these outcomes).

Comparison of time from date of leaflet distribution to symptom presentation was subsequently investigated using Kaplan-Meier survival analysis. The start time for the event (recorded symptom) for both groups was the leaflet distribution date for the intervention group. This start date was therefore treated as a random date for the control group. This approach assumes that the presentation rate (per 4 month period) for the control group would be independent of when that time period began; the analysis investigates whether there is a difference in the distribution of presentations between the two groups. The number of days for those not having a recorded symptom by the record extraction date was censored at 4 months (123 days).

All statistical analyses were performed using two-tailed tests with statistical significance taken at the $5 \%$ level.

\section{Results}

7739 records were extracted from the 8029 originally identified as the intervention group and 7799 were extracted from the 8029 flagged as controls. This discrepancy is likely to be due to records becoming unavailable (e.g. because of moving from the practice or death) in the time between initial group identification and data extraction. The CONSORT flow diagram is shown in Fig. 1.

The data is available from the Zenodo repository [20].

\section{Participant characteristics}

There was no difference between groups as assessed by age or IMD at baseline (see Table 1).

\section{Outcomes data}

Of the 7739 women in the leaflet (intervention) group, 231 had relevant symptoms recorded by their GP in the four-month period following the leaflet distribution (3.0\%). For the 7799 women in the control group, 207 had symptoms recorded in that period (2.7\%). Although there is a slightly higher rate in the intervention group, this does not reach statistical significance at the $5 \%$ level $(\mathrm{RR}=1.11 ; 95 \%$ CI $0.92-1.33 ; \mathrm{z}=1.08 ; p=0.28)$.

The number of days from the date of the leaflet distribution to the date of the first presentation for a symptom indicative of a gynaecological cancer was calculated to investigate whether receipt of the leaflet may have an effect on the delay in symptom reporting by women. For those presenting with a relevant symptom, the mean time to presentation (from the leaflet distribution date) for the control group was 65.2 days ( $\mathrm{sd}=35.0$ days). The intervention group mean time to presentation was nearly 8 days shorter ( 57.2 days; $s d=36.5$ days). This difference was statistically significant $(t=-2.415, \mathrm{df}=474, p=0.016)$. These results are shown in Table 2 .

Figure 2 shows the survival functions for the women in the intervention and control arms.

There was an approximately constant presentation rate over the 4-month period for the control group, whereas the intervention group showed a higher rate of presentations in the 20 days following leaflet distribution, after which the rate was approximately the same as for the control group. This difference did not reach statistical significance (Log Rank (Mantel-Cox) $\chi^{2}=1.42, p=0.23$ ).

In the intervention group, $0.8 \%$ of the women $(n=66)$ were urgently referred compared to $0.7 \%$ of the women in the control group $(n=51)$. This difference did not reach statistical significance at the $5 \%$ level $(R R=1.28$; 95\% CI 0.89-1.85; $\mathrm{z}=1.35 ; p=0.18$ ). 


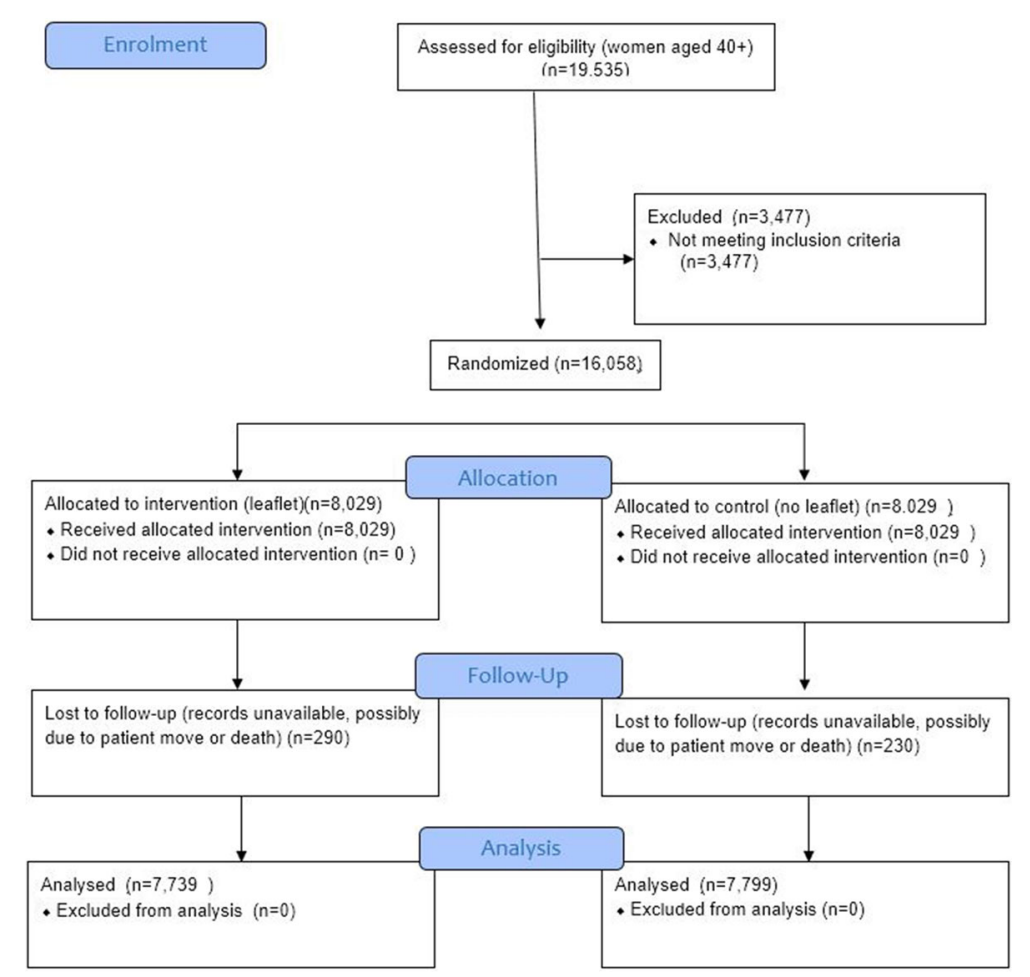

Fig. 1 CONSORT diagram of recruitment, randomisation and analysis of intervention and control groups

The number of days from leaflet distribution to the date of any urgent referral was calculated and compared between the intervention and control groups. The means were 67.7 days ( $\mathrm{sd}=36.9$ days) for the control group and 57.1 days ( $\mathrm{sd}=37.1$ days) for the intervention group. Although this showed a 10-day reduction in the mean time to urgent referral for the intervention group, it did not reach statistical significance $(t=-1.53, \mathrm{df}=114, p=0.13)$.

Three gynaecological cancers were recorded as being diagnosed within the study period (four months following leaflet distribution): two in intervention group patients, and one in the control group.

\section{Discussion}

\section{Summary}

This study is one of the first of its kind to use a randomised controlled trial to quantify the impact of an educational leaflet on rates of, and time to, presentation for possible cancer symptoms in primary care. The differences in rate of gynaecological symptom presentation between intervention and control group were in the direction expected, but not statistically significant $(3.0 \%$ compared with $2.7 \%(\mathrm{z}=1.1 ; p=0.28)$ ). Average time from receiving the leaflet to presentation for those with relevant symptoms was 8 days earlier in the cohort receiving the leaflet than in the control group (where the start time was the date of leaflet distribution to the comparable intervention group) (57 days compared with $65(t=-2.4, p=0.02)$ ). It was not possible to confirm a difference in survival functions when both were compared across the 4 -week follow up (Log Rank (Mantel-Cox) $\chi^{2}=1.42, p=0.23$ ).

\section{Strengths and limitations}

This research demonstrates the potential of record-based methods for evaluating outcomes of general practice interventions. The methodology enabled the testing of a simple intervention across five practices with modest resources. Sources of bias that can affect observational studies were excluded by randomising the distribution of leaflets. Age and index of multiple deprivation were compared between the cohorts, confirming broad similarities. Primary and secondary

Table 1 Participant's baseline characteristics

\begin{tabular}{llll}
\hline Characteristics $^{\mathrm{a}}$ & Intervention & Control & Difference \\
\hline Median age yrs. (IQR $)$ & $58(49-69)$ & $58(49-68)$ & $\mathrm{z}=0.302, p=0.76$ \\
Median IMD (IQR) & $15.4(11.96-22.98)$ & $15.4(11.96-22.98)$ & $\mathrm{z}=-0.444, p=0.66$ \\
\hline
\end{tabular}

aLess than $5 \%$ of records used the recommended codes for ethnicity and therefore no statistical comparison of ethnicity was performed

Inter-Quartile Range 
Table 2 Trial outcomes

\begin{tabular}{llll}
\hline Primary outcomes & Intervention & Control & Difference (control-intervention) \\
\hline Proportion presenting & $231 / 7799(3.0 \%)$ & $207 / 7739(2.7 \%)$ & $\mathrm{RR}=1.11,95 \% \mathrm{Cl} 0.92-1.33 ; p=0.28$ \\
$\begin{array}{l}\text { Time to presentation, Mean, 95\% Cl } \\
\text { Secondary outcomes }\end{array}$ & $57.2(53.4-62.0)$ & $65.2(60.3-70.1)$ & 8 days; $t=-2.42, \mathrm{p}=0.02$ \\
$\quad$ & & & \\
$\quad$ Proportion referred & $66 / 7799(0.8 \%)$ & $61 / 7739(0.7 \%)$ & $\mathrm{RR}=1.28,95 \% \mathrm{Cl} 0.89-1.85 ; \mathrm{p}=0.18$ \\
$\quad$ Time to referral Mean, 95\% Cl & $57.1(48.0-66.1)$ & $67.7(57.4-78.0)$ & 10.6 days; $t=-1.53, p=0.13$ \\
$\quad \begin{array}{l}\text { Other } \\
\quad \text { Cancers diagnosed }\end{array}$ & 2 & 1 & \\
\hline
\end{tabular}

${ }^{a}$ The numbers of cancers diagnosed was not compared statistically due to the small numbers

outcomes were defined in advance with sample size drawn from a separate study that aimed to estimate the likely symptom frequency in general practice populations [16]. Data was extracted and compiled without reference to allocation to intervention or control groups.

As with all record-based studies, the coded items available and extracted may not identify all relevant patients, although the effect of this is likely to be similar in intervention and control groups. In this study, the rate of symptom presentation based on electronic records was considerably less than predicted from estimates based on a questionnaire study [16] which had been used for the a priori sample size calculation. This may have been due to inflated symptom incidence due to survey self-selection bias: it is possible that the questions relating to gynaecological cancer symptoms may have been differentially answered by those having symptoms. Conversely, there may be an under-reporting of symptoms by GPs on electronic patient records. Although the relative risk observed was similar to that used in the sample size calculation (observed $R R=1.11$ compared to estimated $R R=1.13$ ), the observed incidence was approximately one-tenth of the previously published estimate. The actual power of the study was therefore only $20 \%(\alpha=0.05)$ and our study cannot exclude an effect of leaflet distribution on help seeking that could be of importance.

\section{Comparison with existing literature}

Few trials of interventions directed towards early presentation of patients with cancer-related symptoms exist, though it is known that targeted public information leaflets can increase awareness of cancer symptoms [10-12]. A bowel cancer screening study in which leaflets sent to individual patients from practices increased participation in bowel cancer screening programmes by $3-4 \%$ [13] and a study investigating the impact of leaflets on presentation of stroke symptoms delivered as part of a multifaceted campaign [14] are particularly relevant. However,

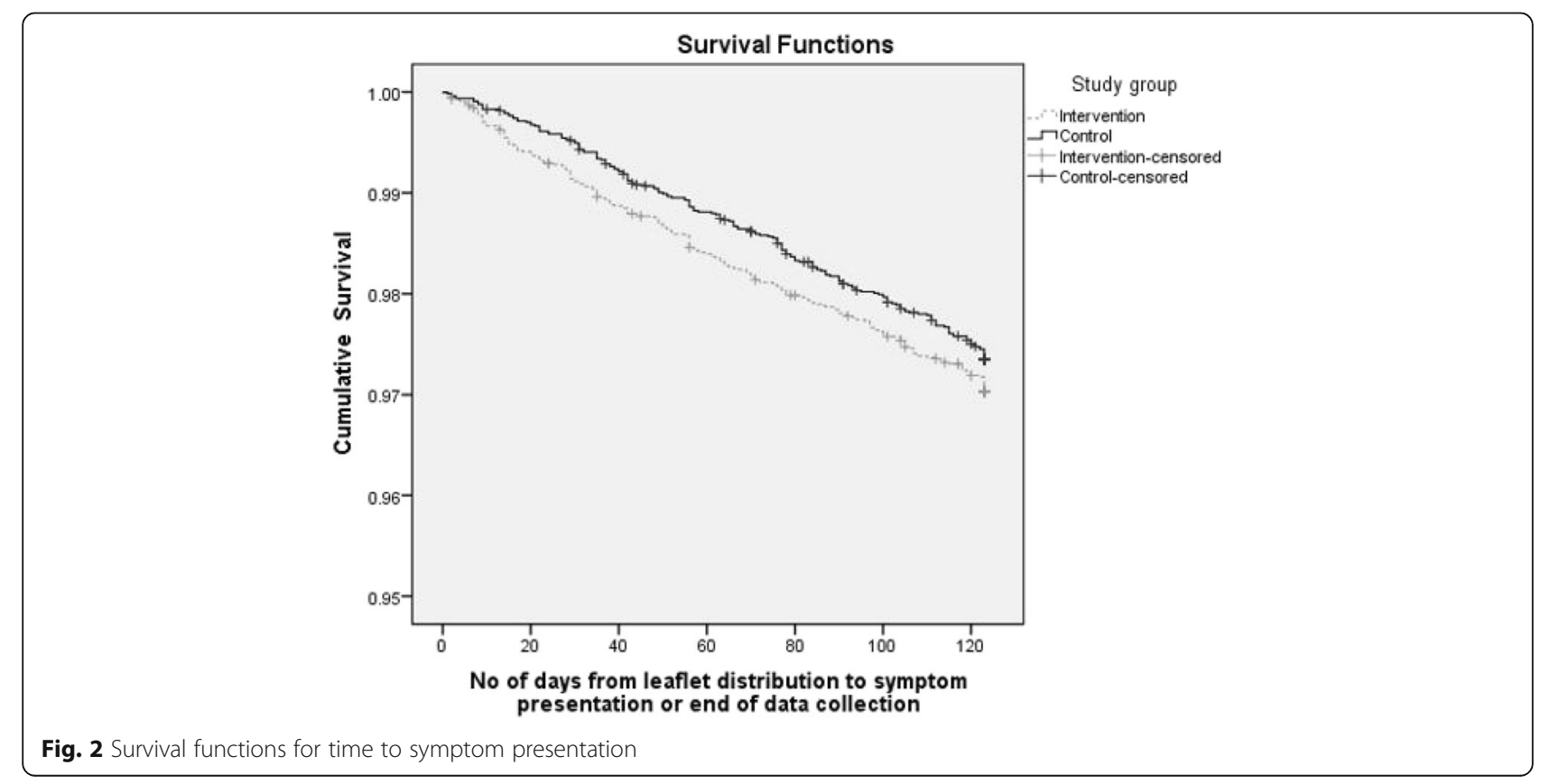


other trials of leaflets promoting colorectal cancer screening have been less successful [21].

This study is one of the first to attempt to systematically quantify the impact of an educational leaflet on rates of, and time to, presentation for potential gynaecological cancer symptoms in primary care. A prior evaluation of the leaflet used in this study demonstrated that its impact on patients' anxiety levels was negligible and changes in anxiety did not influence patients' intentions to seek help [12]. Some evidence for increased rates of presentation in the three weeks after receiving the leaflet was found, but this was a non-significant trend. There was, however, a difference in time to presentation, with women in the intervention group presenting with symptoms just over a week faster than those in the control group. Evidence which quantifies the specific effect of delay to presentation to clinical outcome is lacking in the current literature and the evidence for diagnostic delay is confounded by large effects due to the type of cancer and stage of diagnosis, amongst other factors $[2,22]$. However, given that the NHS has a target of 14 days from presentation at GP to specialist consultation for suspected cancers, an additional delay of 8 days is intuitively clinically important and is an important effect in the context of possible public health impact.

\section{Implications for research and practice}

The National Awareness and Early Diagnosis Initiative (NAEDI) was launched in the United Kingdom as part of a strategy to improve cancer outcomes. The key hypothesis underpinning NAEDI was that delays lead to cancer patients being diagnosed with more advanced disease and thus experiencing poor 1-year and 5-year survival rates. An investigative phase was followed by piloting and then definitive regional, disease -focused campaigns directed towards raising public awareness of symptoms and signs of common cancers [23]. The model adopted was typically focused on single awareness-raising messages using posters and leaflet distribution in conjunction with social marketing through radio and television. Campaigns have had variable outcomes, with one campaign to promote early diagnosis of lung cancer claiming some success [24], and mixed results from campaigns directed towards bowel cancer, urological cancer and ovarian cancer [25-28].

Attempts have been made to evaluate process and outcome, with urgent cancer referrals most often used as a proxy outcome. Where effects have been noted it remains difficult to be clear what impact the components of different campaigns might have, and in particular the value of local distribution of leaflets. Evidence that a low-intensity intervention such as leaflet distribution may decrease the patient interval for potential cancer symptoms lends support to pursuing this type of approach as part of a wider strategy for reducing the time to cancer diagnosis. This study does not provide reliable estimates for the likely impact on GP consultations or urgent referrals, but these could be derived in a larger randomised trial or observational study.

\section{Conclusions}

This study is one of the first to attempt to systematically quantify the impact of an educational leaflet on rates of, and time to presentation for potential cancer symptoms in primary care. There was some evidence for increased rates of presentation in the three weeks after receiving the leaflet, but this was not statistically significant. There was a significant difference in time to presentation, with women in the intervention group presenting with symptoms just over a week faster than those in the control group. The evidence that this low-intensity intervention may decrease time to presentation for potential cancer symptoms lends support to pursuing this type of approach as part of a wider strategy for reducing the time to cancer diagnosis.

\section{Abbreviations}

CAPI: Computer Assisted Personal Interviewing: Cl: Confidence Interval; CONSORT: Consolidated Standards of Reporting Trials; GP: General Practitioner; IMD: Index of Multiple Deprivation (IMD); LSOA: Lower Layer Super Output Areas; n: number; NRES: National Research Ethics Service; RCT: Randomised Control Trial; REC: Research Ethics Committee; RR: Relative Risk; sd: Standard deviation; UK: United Kingdom

\section{Acknowledgements}

We are grateful for the support of Dr. Saqib Mirza, the EMCN GP lead, and colleagues at Corby and Nene Clinical Commissioning Groups for help in engaging and recruiting practices and the support of the Northamptonshire R\&D Service. We would like to thank Simon Lusignan at the University of Surrey and Mandeep Sekhon at City University for advice in extracting and interpreting the dataset.

\section{Funding}

This study was part of a programme of work of the National Institute for Health Research Collaboration for Leadership in Applied Health Research and Care (Leicestershire, Northamptonshire and Rutland and East Midlands) and was funded by Cancer Research UK and the National Cancer Action Team through the East Midlands Cancer Network. AS and JW received funding from NAEDI which supported the development and design of an associated observational study on which this trial is based. JW is funded by a Career Development Fellowship from Cancer Research UK.

\section{Availability of data and materials}

The datasets generated during this study and the protocol are available in the Zenodo repository, https://doi.org/10.5281/zenodo.846744 [20].

\section{Authors' contributions}

All authors (JC, KV, SR, MP, AS, JW) made substantial contributions to the design of the study and have been involved in writing and editing the manuscript. All authors have read and approved the final manuscript. JC was the Principal Investigator for the study and analysed the data. KV wrote the SystmOne queries and extracted the data. SR provided clinical advice and interpretation. AS and JW developed the leaflet intervention. MP advised on ethical issues.

\section{Ethics approval and consent to participate}

The research project was approved by the NRES Committee East Midlands Nottingham 1 (REC reference: 13/EM/042). This included approval for the collection and analysis of anonymised, retrospective data from patient records without individual consent. 


\section{Consent for publication}

Not applicable.

\section{Competing interests}

The authors declare that they have no competing interests.

\section{Publisher's Note}

Springer Nature remains neutral with regard to jurisdictional claims in published maps and institutional affiliations.

\section{Author details}

${ }^{1}$ Faculty of Health and Society, University of Northampton, Northampton NN2 7AL, UK. ${ }^{2}$ Sandy Close, Wellingborough NN8 5AY, UK. ${ }^{3}$ Department of Health Sciences, University of Leicester, 22-28 Princess Road West, Leicester LE1 6TP, UK. ${ }^{4}$ Faculty of Health and Society, University of Northampton, Northampton NN2 7AL, UK. ${ }^{5}$ Centre for Implementation Science, Institute of Psychiatry, Psychology and Neuroscience, King's College London, 16 De Crespigny Park, Camberwell, London SE5 8AF, UK. ${ }^{6}$ Department of Behavioural Science and Health, University College London, 1-19 Torrington Place, London WC1E 6BT, UK.

Received: 6 March 2018 Accepted: 31 July 2018

Published online: 09 August 2018

\section{References}

1. Cancer Research UK. Cancer Statistics for the UK 2017. http://www. cancerresearchuk.org/health-professional/cancer-statistics.

2. Thomson CS, Forman D. Cancer survival in England and the influence of early diagnosis: what can we learn from recent EUROCARE results? $\mathrm{Br} J$ Cancer. 2009;101(Suppl 2):S102-9.

3. Macdonald S, Macleod U, Campbell NC, Weller D, Mitchell E. Systematic review of factors influencing patient and practitioner delay in diagnosis of upper gastrointestinal cancer. Br J Cancer. 2006;94(9):1272-80

4. Mitchell E, Macdonald S, Campbell NC, Weller D, Macleod U. Influences on pre-hospital delay in the diagnosis of colorectal cancer: a systematic review. Br J Cancer. 2008:98(1):60-70.

5. Scott SEWF, Webster A, Sutton S, Emery J. The model of pathways to treatment: conceptualization and integration with existing theory. $\mathrm{Br}\rfloor$ Health Psychol. 2013;18(1):45-65

6. Low EL SA, Lyons J, Romney-Alexander D, Waller J. What do British women know about cervical cancer symptoms and risk factors? Eur J Cancer. 2012; 48:3001-8.

7. Low EL WJ, Menon U, Jones A, Reid F, Simon AE. Ovarian cancer symptom awareness and anticipated time to help-seeking for symptoms among UK women. J Fam Plann Reprod Health Care. 2013;39:163-71.

8. Cooper CP, Polonec L, Stewart SL, Gelb CA. Gynaecologic cancer symptom awareness, concern and care seeking among US women: a multi-site qualitative study. Fam Pract. 2013;30:96-104

9. Robb K, Stubbings S, Ramirez A, Macleod U, Austoker J, Waller J, Hiom S, Wardle J. Public awareness of cancer in Britain: a population-based survey of adults. Br J Cancer. 2009;101(Suppl 2):S18-23.

10. Austoker J, Bankhead C, Forbes LJL, Atkins L, Martin F, Robb K, Wardle J, Ramirez AJ. Interventions to promote cancer awareness and early presentation: systematic review. Br J Cancer. 2009;101(Suppl 2):S31-9.

11. Linsell L, Forbes LJL, Kapari M, Burgess C, Omar L, Tucker L, Ramirez AJ. A randomised controlled trial of an intervention to promote early presentation of breast cancer in older women: effect on breast cancer awareness. Br J Cancer. 2009:101(Suppl 2):S40-8.

12. Morris M, Friedemann-Smith C, Boxell E, Wardle J, Simon A, Waller J. Quantitative evaluation of an information leaflet to increase prompt helpseeking for gynaecological cancer symtpoms. BMC Public Health. 2016;16:374

13. Wardle J, Williamson S, McCaffery K, Sutton S, Taylor T, Edwards R, Atkin W. Increasing attendance at colorectal cancer screening: testing the efficacy of a mailed, psychoeducational intervention in a community sample of older adults. Health Psychology: Official Journal Of The Division Of Health Psychology, American Psychological Association. 2003;22(1):99-105.

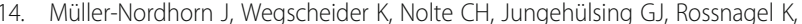
Reich A, Roll S, Villringer A, Willich SN. Population-based intervention to reduce prehospital delays in patients with cerebrovascular events. Arch Intern Med. 2009;169(16):1484-90.
15. Boxell EM, Smith SG, Morris M, Kummer S, Rowlands G, Waller J, Wardle J, Simon AE. Increasing awareness of gynecological cancer symptoms and reducing barriers to medical help seeking: does health literacy play a role? J Health Commun. 2012:17(Suppl 3):265-79.

16. Low EL, Simon AE, Waller J, Wardle J, Menon U. Experience of symptoms indicative of gynaecological cancers in UK women. Br J Cancer. 2013;109(4):882-7.

17. Kumarapeli P, Stepaniuk R, de Lusignan S, Williams R, Rowlands G: Ethnicity recording in general practice computer systems. Journal Of Public Health (Oxford, England) 2006, 28(3):283-287.

18. UK Data Service: GeoConvert 2016 In: [http://geoconvert.mimas.ac.uk/].

19. Department of Communities and Local Government: English Indices of Deprivation 20102016 In: [https://www.gov.uk/government/statistics/ english-indices-of-deprivation-2010]

20. Campbell J, Vaghela K, Rogers S, Pyer M, Simon A, Waller J: Evaluating the impact of a leaflet to raise awareness in women of symptoms of gynaecological cancers in primary care: datasets 2017 In: Zenodo; [https:// doi.org/10.5281/zenodo.846744].

21. Wardle J, von Wagner C, Kralj-Hans I, Halloran SP, Smith SG, McGregor LM, Vart G, Howe R, Snowball J, Handley G et al: Effects of evidence-based strategies to reduce the socioeconomic gradient of uptake in the English NHS Bowel Cancer Screening Programme (ASCEND): four clusterrandomised controlled trials. Lancet (London, England) 2016, 387(10020): 751-759.

22. Crawford SC, Davis JA, Siddiqui NA, de Caestecker L, Gillis CR, Hole D, Penney $G$. The waiting time paradox: population based retrospective study of treatment delay and survival of women with endometrial cancer in Scotland. BMJ. 2002;325(7357):196.

23. Richards MA. The National Awareness and early diagnosis initiative in England: assembling the evidence. Br J Cancer. 2009;101(Suppl 2):S1-S4.

24. Ironmonger L, Ohuma E, Ormiston-Smith N, Gildea C, Thomson CS, Peake MD. An evaluation of large scale interventions to raise public awareness of a lung cancer symptom. Br J Cancer. 2015;112:207-16.

25. Bethune R, Marshall MJ, Mitchell SJ, Oppong C, Cartmel MT, Arumugam PJ, Gee AS, Daniels IR. Did the 'be clear on bowel Cancer' public awareness campaign pilot result in a higher rate of cancer detection? Postgrad Med J. 2013;89:1261-71.

26. Hughes-Hallett A, Browne D, Mensah E, Vale J, Mayer E. Assessing the impact of mass media public health campaigns. Be clear on Cancer 'blood in pee': a case in point. Brit J Urol. 2016;117:570-5.

27. National Cancer Intelligence Network: Be clear on Cancer:ovarian cancer awareness regional pilot campaign. London; 2015. http://www.ncin.org.uk/ cancer_type_and_topic_specific_work/topic_specific_work/be_clear_on_ cancer/ovariancancerevalutionresults.

28. Peacock O, Clayton S, Atkinson F, Tierney GM, Lund JN. 'Be clear on Cancer': the impact of the UK National Bowel Cancer Awareness Campaign. Color Dis. 2013;15:963-7.

Ready to submit your research? Choose BMC and benefit from:

- fast, convenient online submission

- thorough peer review by experienced researchers in your field

- rapid publication on acceptance

- support for research data, including large and complex data types

- gold Open Access which fosters wider collaboration and increased citations

- maximum visibility for your research: over $100 \mathrm{M}$ website views per year

At $\mathrm{BMC}$, research is always in progress.

Learn more biomedcentral.com/submissions 